\title{
Study of Problems and Countermeasures in Public Recruitment of Business Units in the Internet Era
}

\author{
Xiaoling Li Chengqing Yu \\ Hainan College of Economics and Business Haikou, Hainan Province
}

Keywords: internet+, business unit, public recruitment, current situation, improvement.

\begin{abstract}
Internet+ era, with the development of network information technology and the improvem ent of the economic level, people also gradually improve the social demand for public institutions, $h$ ope can be more efficient, better public services, so the institution reform has become the research a nd practice of the urgent matters. The success of business unit's reform depends on the reform of human resource system to great extent, and the high-quality human resource group is the important premise to ensure the development of business units. By mastering the entrance pass and implement the public recruitment scientifically, it introduces more high-quality talents for business units, so as to improve the quality of the entire team and work quality.
\end{abstract}

\section{Introduction}

Internet+ era,The convenience and efficiency of network communication promote more close ties among countries all over the world. When Chinese enterprises and markets are melting into the big environment of world economy, Chinese human resource market has also taken part in the competition of international talents more profoundly as one part of global human resource market. Compared to the development speed of enterprise human resource system, the step of business units is slightly slow. As the business units engaging in medicine, education, sanitation, sports, culture, news and so on, it is the important field to enhance comprehensive national power and implement the strategy of rejuvenating the nation by science and education, but the deficiency and leakage of talents has posed severe challenges. In 2012 business unit public recruitment of Sanya, the examinee Cai passed the interview with the score of 4.55 , which aroused the doubt from the public. Although Cai had given up the interview after this event was announced by the media, it still triggered the guess by endless netizens on this event. The response of Sanya human resource and social security ministry is that this recruitment exam has not included any illegal behavior. However, the exposure of this event has brought certain property of damage to the public image of business units. For extensive examinee who are actively preparing to take part in the national civil servant exam, how to ensure the fair, standard and scientific recruitment system has become the urgent problem. Because the domestic business unit's traditional manpower system is established on the concentrated planned economy system and cadre management system, business units lack the autonomous rights, decrease the efficiency and have the heavy official standard concepts. This paper will analyze the problems existing in the domestic business unit's public recruitment, and put forward countermeasures to the public recruitment of domestic business units. It allocates the business unit's manpower reasonably and improves their social service ability. 


\section{The characteristics of public recruitment in business units}

Business unit's public recruitment and civil servant's enrollment system is the important contents of domestic public department's human resource development and management. In the practice of public recruitment, most of business units imitate the exam and enrollment system of civil servants. However, compared to civil servant's team, business units have their own characteristics and properties, which will make the recruitment of business units have their own characteristics. When competition has become the internal requirement, the personnel system of business units also introduced the competition mechanism. In November $16^{\text {th }}$ of 2008 , No. 6 Order Temporary Regulations for Public Recruitment in Business Units was released by Ministry of Personnel of People's Republic of China, which defined that public recruitment must be implemented for new staffs of business units except for national political placement, the personnel employed by superiors according to cadre personnel administrative authority and other confidential posts. The post category in business units are complex, and major division is various. Compared to civil servants and enterprise recruitment, the public recruitment has the following features:

\section{The requirement of having working experiences}

Because the personnel recruitment of business units starts from the angle of "staff employment" instead of "talent cultivation". Most of employers wish new staffs to "enter the state" immediately and adapt to the new work environment in the shortest period.

\section{High professional requirements}

Compared to civil servants, the administrative properties of business units are relatively lower, and the proportion of specific operation and implementation has increased. For these posts, personal professional technical level affects working effects more than the ordinary qualities of this person.

\section{Dispersed recruitment time}

The liquidity of business unit personnel is higher than civil servants, working contents are not as stable as those in governmental organs, the situation that personnel are in shortage and need adjusting may appear at any time. Therefore, the recruitment time of business units is quite hard to maintain consistent, which has the features of large quantities, short periods and fast time-effects.

\section{High social attention}

The public recruited posts in business units are authorized, highly guaranteed and have the better treatment. For the competition fierce degree of partial posts, it is no less than that of civil servants, especially in some first-tier cities, the social attention degree is higher, which requires the recruitment process to be equal, just and open.

\section{Analysis of problems existing in business unit's public recruitment}

After the popularization of civil servant's exam application, the recruitment of business units has heated up as well. For hot posts in numerous places, over thousands of people strive for one post. It can be seen that the influential power and social public acceptance of business units are expanding increasingly. However, domestic public recruitment system started late, and its practice period is not long period. In the current period, it still exists the weakness of incomplete system, deficiency 
technical guarantees and imperfect practical implementation and so on.

(I) System layer

1. Incomplete legal and regulatory system, lower legislation level

Since reform and opening up, our country has successively released a series of laws and regulations to reflect object rules. On the exam and enrollment system of civil servants, it establishes and releases Civil Servants Act. In Civil Servants Act, it makes specific regulations for exam and enrollment system, which provides powerful legal evidence for domestic exam employed civil servants. After this system, most of new business unit staffs are publicly recruited. However, in terms of regulations made for public recruited staffs in business units, there are only Temporary Regulations for Public Recruited Personnel issued by National Ministry of Personnel and corresponding public recruitment leaflets released by each local personnel department, it still lacks a law built by National People's Congress. The regulations made for the public recruitment of Temporary Regulations for Public Recruited Personnel are only in the macroscopic sense, which is still blank in operational and microscopic aspects. Specifically, when some local business units are making public recruitment, employment discrimination appears, such as the constraint of recruitment range as the local household. However, until now, our country has not made any regulation on employment discrimination. In addition, testing question composition, examiner selection and the supervision and management of the whole process also lacks the effective legal and regulatory proof.

2. Lack related matching system

Business unit's public recruitment system is not existing singularly, which affects and constrains employment system and personnel agent system of units mutually. In Article 25, Chapter 5 of Temporary Regulations for Public Recruited Personnel in Business Units, it points out, "when the legal representative or entrusting person of employing units signs the employment contract with the employee, the personnel relations are confirmed." However, until now, numerous domestic staffs of business units are lifelong tenure, without any ordinary establishment of employment system.

(II) Practical operation aspects

\section{Narrow information transmission aspects}

The recruitment information of business units is usually released by few local medias and the websites of supervisor department, which touches small public range, and the release information channel is singular. It not only affects the recruitment effects, but also makes the social public doubtful at the equity of recruitment process. In Temporary Regulations for Public Recruitment in Business Units, it regulates the public recruitment programs, including the links of recruitment plans, releasing recruitment information, application and investigation, exams and assessment, physical checking, publicity and signing employment contracts. Although there are strict written regulations, in the practical implementation, it is still random in the recruitment procedure of business units.

2. The science property of exam methods remains improving, lacking the creativity

In numerous foreign countries, some methods to assist evaluation are ordinarily adopted, such as psychological tests, scenario testing and official document testing. In some areas, personnel recruitment usually uses a piece of paper to choose different types of personnel, exam subjects and content setting are random, which cannot ensure the science of exams. In addition, repeated propositions and paper inspection may appear in similar posts and same majors. In summary, exam costs are high, wasting a lot of resources. 


\section{Lack effective recruitment and enrollment feedback and evaluation}

In public recruitment of business units, most of units have not made sufficient cost accounting and effect assessment of recruitment results. Usually, it is believed that it is fine when the post can recruit personnel, which lacks the matched quality assessment system to make the objective assessment analysis on the entire effects, the follow-up and feedback of every link, as well as the assessment and summary of recruitment quality and efficiency. In order to develop the future recruitment work better, it is quite necessary to evaluate the previous recruitment, which can help modify the errors in the process.

4. Organization work of recruitment remains improving

Some units adopt self-proposition, which cannot ensure the equity and confidentiality of propositions. Interviewing examiners and related examinee staffs have not received professional training as well, and their professional level, organizational ability, judging abilities and standards remain improving. In addition, due to the weak legal concepts and the existence of ruling by men, the supervision link in the business unit's public recruitment management is rather weak. Recruitment and enrollment has not formed the effective supervision mechanism, and there is no complete recruitment supervision system, leading the supervision range to be narrow, contents are not comprehensive, the supervision of interviews and written exams are not detailed or specific enough.

\section{Countermeasures and advice to improve business unit's public recruitment}

For the recruitment work in business units, in the aspect of improving the validity and reliability of interviews, it should master the assessment factors precisely, improve the overall quality of examiners, study and recognize the characteristics of examinee. In specific, several aspects in the following can be done to improve the recruitment of business units:

1. Fully develop the utility of network information

Recruitment exams for business units have the characteristics of large quantity, short cycle and fast time-effects. Therefore, it can fully use network information technical means to provide convenience for enrollment units and registered examinee. Such as unitedly publishing the information of the whole province, online registration, registration qualification checking, online printing admission cards, recruited post information inquiry, computer-based testing and so on can shorten work cycles and implement the transparent exam enrollment programs.

With the rapid development of the Internet and the rapid development of computer technology and communication technology, online recruitment, a new recruitment mode, is more and more pop ular with most employers. The extensive application of online registration system can change the tra ditional registration method, which not only reduces the workload of the personnel department, but also greatly facilitates the applicants to participate in the registration, which can improve the efficie ncy of recruitment. The establishment of a more perfect recruitment system is the only way to realiz e the information and modernization of the recruitment of public institutions, and is the future trend of open recruitment and management of information and networking, which is of far-reaching signif icance.

2. Tight procedures, improve the standard property, acquire the support from related laws and regulations

Five passes are mainly reflected: Firstly, post setting pass, set posts for affairs, avoid the appearance of setting posts for people. Secondly, master the pass of registration, examination. Avoid personnel who are not matched with exam application requirements to mix in. Thirdly, control the 
pass of proposition. Make requirements on proposition personnel, proposition programs and proposition standards, ensure the quality and security of test questions, put an end to question release. Fourthly, master the pass of interviews. Set interview examiner groups scientifically, enhance the training of interviewing examiners, unit responsible persons should avoid as much as possible. Fifthly, the pass of score management. Ensure the independence and standardization of score generation, build the supervision and testing mechanism of examinee and society.

3. Mutual existence of multiple recruitment means

The purpose of staff employment system in business units is to establish the competition that selects the superiors and eliminate the inferiors and fulfills vitality. In the aspect of setting posts, according to the professional knowledge and work abilities of post requirements, it adopts the recruitment mechanism including internal recruitment, external recruitment, online recruitment and other multiple recruitment means.

4. Innovative exam methods

At present, the testing projects of commonly used business units are: public basic knowledge, administrative professional ability, arguments and structuring exams. Employer units can organize exams according to post classification. The posts of business units can be totally divided into three types: management post, professional technical post and ground posts. The abilities and knowledge structure requirements of these three posts of staffs are also different. Therefore, in the process of public recruitment, there should be exams for these three posts, except for original written exams, structuring interviews and other exam methods, various psychological measuring technologies, comment center technologies can be the important supplement of existing traditional evaluation means as well.

\section{Conclusion}

In public recruitment work, how to ensure the social equity of public recruitment work in business units and how to do the public recruitment work scientifically and effectively is the difficulty of this paper. For the thing of business unit's public recruitment in the growth period, the study of this paper is just a primary exploration, which still exists a lot of deficiencies.

The vigorous development of information technology makes the whole society gradually into $t$ he era of global network. The establishment of the open recruitment system relying on the network i s the key to the reform of the cognitive system of the institutions, and also the innovation of the inst itutions in the employment. The implementation of the network open recruitment system has broade ned the channels for people to enter the institutions, and changed from random to normative success , providing a fair competition platform for the candidates. The open recruitment network with its lo w cost, fast transmission, large information, wide coverage and other advantages, has become an inc reasingly common pattern of recruitment, institutions should vigorously promote and try to improve the network open recruitment, make open and effective network channels to better serve the busine ss unit recruitment. At the same time, can also use the network supervision and assessment of the op en recruitment, let the business unit recruitment "Internet plus" follow the pace of the times.

\section{Acknowledgements}

This paper is the Hainan Provincial Department of education project (Hnky2016-62): "one of the students in Higher Vocational Colleges of Hainan province occupation career planning research and application of the achievements of the new environment The Belt and Road". 


\section{References}

[1]Lu Xiaohui. Study and Thinking of Public Recruitment Work in Business Units in China[D].Shandong University,2010.

[2]Ma Sifeng.Countermeasures and Thinking of Public Recruitment Work in Business Units[D].Shandong University,2011.

[3]Chen Chen. Study of Public Recruitment Work in Business Units [D].ZhengZhou University,2012.

[4]Chen Yungui. Investigation and Thinking of Public Recruitment System Implemented by Business Units[J]. Hengyang Communication,2009,5.

[5]Liu Jibin. Practice and Thinking of Public Recruitment Work in Business Units[J].Personnel Talents,2008,10

[6]Zhu Liangfeng. Tianjin: Business Unit Public Recruitment Exam Score Should be No less than 50\% of the Total Score[J]. Dynamics Within Industries. 2011,2 